\title{
Cerebellar Dysfunction Explains the Extinction-Like Abolition of Conditioned Eyeblinks After NBQX Injections in the Inferior Olive
}

\author{
Svitlana Zbarska, James R. Bloedel, and Vlastislav Bracha \\ Department of Biomedical Sciences, Iowa State University, Ames, Iowa 50011
}

\begin{abstract}
Classical conditioning of the eyeblink response is a form of motor learning that is controlled by the intermediate cerebellum and related brainstem structures. The inferior olive (IO) is commonly thought to provide the cerebellum with a "teaching" unconditioned stimulus (US) signal required for cerebellar learning. Testing this concept has been difficult because the IO, in addition to its putative learning function, also controls tonic activity in the cerebellum. Previously, it was reported that inactivation of AMPA/kainate receptors in the IO produces extinction of conditioned responses (CRs), suggesting that it blocks the transmission of US signals without perturbing the functional state of the cerebellum. However, the electrophysiological support for this critical finding was lacking, mostly because of methodological difficulties in maintaining stable recordings from the same set of single units throughout long drug injection sessions in awake rabbits. To address this critical issue, we used our microwire-based multiple single-unit recording method. The IO in trained rabbits was injected with the AMPA/kainate receptor blocker, 1,2,3,4-tetrahydro-6-nitro-2,3-dioxo-benzo[f]quinoxaline-7-sulfonamide (NBQX), and its effects on CR expression and neuronal activity in the cerebellar interposed nuclei (IN) were examined. We found that NBQX abolished CR expression and that delayed drug effects were independent of the presentation of the conditioned stimulus and were therefore not related to extinction. In parallel to these behavioral effects, the spontaneous neuronal activity and CR-related neuronal responses in the IN were suppressed, suggesting cerebellar dysfunction. These findings indicate that testing the role of IO in learning requires methods that do not alter the functional state of the cerebellum.
\end{abstract}

Key words: inferior olive; interposed nucleus; classical conditioning; rabbit; extinction; AMPA/kainate receptor

\section{Introduction}

Classical conditioning of the eyeblink response is a form of motor learning that critically depends on the intermediate cerebellum. Lesioning or inactivation of the interposed nuclei (IN; the output of the intermediate cerebellum) prevents acquisition of new conditioned responses (CRs) as well as the expression of previously acquired CRs (McCormick and Thompson, 1984; Yeo et al., 1985; Welsh and Harvey, 1989; Bracha et al., 1994; Krupa and Thompson, 1997). A popular explanation for the CR's cerebellar dependency is the cerebellar learning hypothesis. According to this concept, the intermediate cerebellar cortex, and to a lesser degree the IN, receive information about the conditioned stimulus (CS) via mossy fibers and about the unconditioned stimulus (US) via climbing fibers. It has been postulated that during learning the interactions between mossy and climbing fiber inputs at points of their convergence induce plastic changes that make the cerebellum more responsive to mossy fiber CS input. The en-

Received July 26, 2007; revised Nov. 9, 2007; accepted Nov. 10, 2007.

This work was supported by National Institutes of Health Grants R01 NS36210 and R01 NS21958. We thank Steven Ryan for assistance with the experimental set up, Kari Teeter for assistance with histology, and Gary Zenitsky for assistance with statistical analysis and manuscript preparation.

Correspondence should be addressed to Dr. Vlastislav Bracha, Department of Biomedical Sciences, lowa State University, 2032 Vet Med, Ames, IA 50011. E-mail: vbracha@iastate.edu.

DOI:10.1523/JNEUROSCI.3403-07.2008

Copyright $\odot 2008$ Society for Neuroscience $\quad$ 0270-6474/08/280010-11\$15.00/0 hanced responses to the CS are thought to generate CRs (Marr, 1969; Thompson, 1986).

The inferior olive (IO), which is the exclusive source of cerebellar climbing fibers, is a pivotal structure within the cerebellar learning hypothesis framework. Based on this proposal, the IO provides the cerebellum with a "teaching" US signal. If so, blocking the IO input to the cerebellum should prevent CR acquisition and it should also extinguish previously learned CRs (McCormick et al., 1985; Mintz et al., 1994). Confirming these predictions experimentally has been difficult because blocking the IO input to the cerebellum produces incapacitating shifts in tonic activity within eyeblink circuits. Inactivating the IO increases the firing rate of cerebellar Purkinje cells, which in turn inhibit cerebellar output nuclei (Montarolo et al., 1982; Benedetti et al., 1983; Batini et al., 1985). This physiological mechanism interferes with testing the learning-related function of the IO. For example, when examining whether IO inactivation extinguishes CRs, we provided evidence that the GABA-A agonist muscimol and the broad-spectrum glutamate receptor antagonist $\gamma$-D-glutamylglycine (DGG) each abolished CRs not because of extinction, but simply because of tonic dysfunction of cerebellar circuitry (Zbarska et al., 2007). However, in a separate study, Medina et al. (2002) reported the intriguing finding that injecting the AMPA/ kainate receptor antagonist, 1,2,3,4-tetrahydro-6-nitro-2,3dioxo-benzo[f] quinoxaline-7-sulfonamide (NBQX), in the IO 

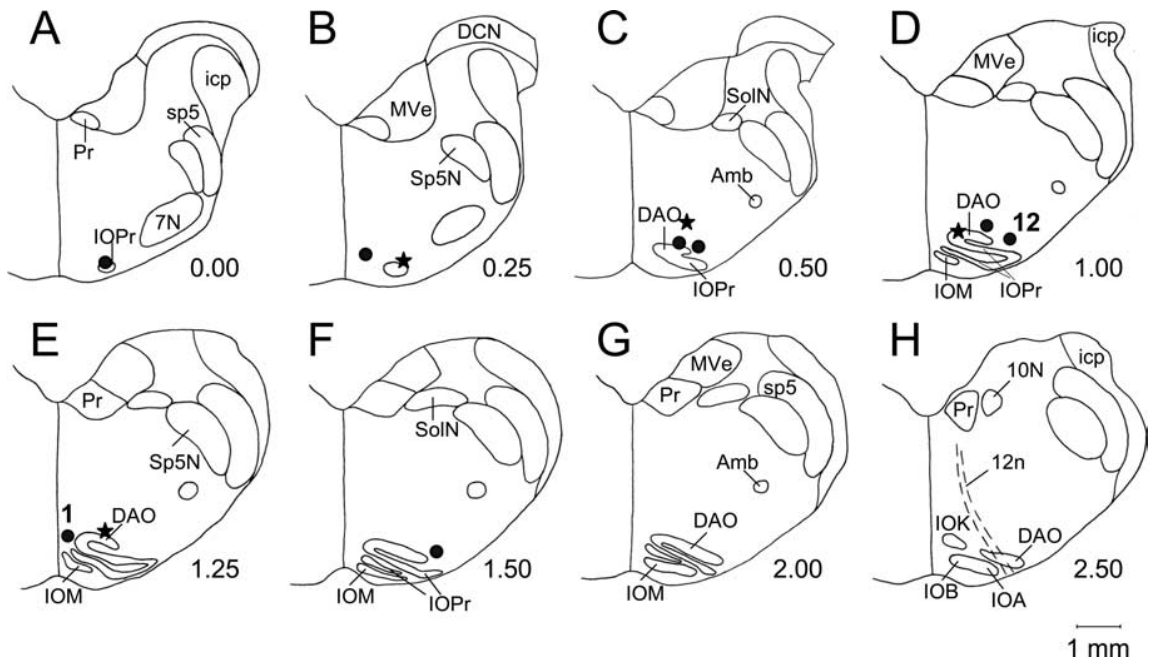

Figure 1. Location of injection sites in the I0 injection group $(\mathbf{O} ; n=8)$ and in the IN recording group $(\star ; n=4)$. $\boldsymbol{A}-\boldsymbol{H}$, The identified sites in individual animals were transferred to a set of standardized coronal sections of the rabbit medulla, arranged in rostral-to-caudal order. The anterior-posterior distance in millimeters from the rostral pole of the 10 is on the lower right side of each section. All injection sites were found within or close to the rostral part of the inferior olivary complex. Injections of NBQX at all marked sites abolished CR expression. Injection site labeled "1" yielded an immediate CR abolition after a $1.0 \mu$ l injection of either 150 or $19 \mu \mathrm{M}$ NBQX. The site labeled 12 was the least effective because CR abolition required $3.5 \mu$ l of $150 \mu \mathrm{M}$ NBQX injected over $35 \mathrm{~min}$. DA0, Dorsal accessory inferior olive; 10M, medial inferior olive; IOPr, principal inferior olive; I0A, subnucleus A of the medial inferior olive; IOB, subnucleus B of the medial inferior olive; IOK, cap of Kooy of the medial inferior olive; Sp5N, spinal trigeminal nucleus; sp5, spinal trigeminal tract; Pr, prepositus hypoglossal nucleus; 7N, facial nucleus; icp, inferior cerebellar peduncle; MVe, medial vestibular nucleus; SoIN, solitary nucleus; Amb, ambiguous nucleus; 12n, hypoglossal nerve; 10N, dorsal motor nucleus of the vagus; DCN, dorsal cochlear nucleus.

suppressed CRs in an extinction-like manner. Did injecting the IO with NBQX affect US signals selectively while preserving normal tonic activity of the cerebellum? This is a pivotal question because an affirmative answer would strongly support an IO "teaching" function. To address this issue, we used an advanced method of long-term single-unit recording in pretrained rabbits while we microinjected NBQX in the IO to assess simultaneously the effects of this manipulation on CR expression and the responses and tonic activity of IN neurons. Here, we report that blocking AMPA receptors in the IO abolishes CRs by suppressing both the tonic and CR-related neuronal activity in the IN and that the delayed (extinction-like) behavioral effects of NBQX most likely stem from the diffusion of injected drug.

\section{Materials and Methods \\ Subjects}

Fifteen male New Zealand White Rabbits (Harlan, Indianapolis, IN), weighing $2.5-3.0 \mathrm{~kg}$ (3-4 months old at the beginning of experiments), were used in these studies. Twelve rabbits were included in a study examining the effects of IO inactivation on CR expression (IO injection group). Four animals were used in experiments testing the effects of IO inactivation on CRs and on neuronal activity in the IN (IN recording group). Rabbits were housed individually on a 12/12 h light/dark cycle and provided with food and water ad libitum. All experiments were performed in accordance with the National Institutes of Health's Principles of Laboratory Animal Care (publication No. 86-23, revised 1985), the American Physiological Society's Guiding Principles in the Care and Use of Animals, and the protocol approved by Iowa State University's Committee on Animal Care.

\section{Surgery}

Before any training, all animals were implanted either with an injection cannula or with both an injection cannula and recording hardware using sterile surgical techniques. Rabbits were anesthetized with a mixture of ketamine $(50 \mathrm{mg} / \mathrm{kg})$, xylazine $(6 \mathrm{mg} / \mathrm{kg})$, and acepromazine $(1.5 \mathrm{mg} / \mathrm{kg})$ and placed in a stereotaxic apparatus with $\lambda$ positioned $1.5 \mathrm{~mm}$ below bregma. After exposing the skull, three stainless steel anchor screws and a 28-gauge injection guide tube were implanted. For targeting anterior parts of the right IO, the following stereotaxic coordinates (relative to $\lambda$ ) were used: anteroposterior (AP), $x-(0.69 x+4.5)$ $\mathrm{mm}$ anterior to $\lambda$ ( $x$ is horizontal distance between bregma and $\lambda$ in $\mathrm{mm}$ ), mediolateral (ML), $1.0 \mathrm{~mm}$ lateral to $\lambda$, and dorsoventral (DV), $22.4 \mathrm{~mm}$ ventral to $\lambda$. The patency of the injection guide tube was protected between experiments by a 33-gauge stainless-steel stylet.

The four rabbits in the IN recording group were also implanted with a microelectrode array/micromanipulator assembly targeting the left IN as in the study by Aksenov et al. (2004). The manipulator contained three bundles of microwire electrodes totaling 14 electrodes (stainless steel, $18 \mu \mathrm{m}$ diameter, Formvar insulation). The microwires were connected to a 15-pin connector embedded in dental acrylic. The stereotaxic coordinates for the IN implant were as follows: AP, $x-(0.69 x$ $+4.8) \mathrm{mm}$ anterior to $\lambda$ ( $x$ is distance between bregma and $\lambda$ in $\mathrm{mm}$ ); ML, $5.0 \mathrm{~mm}$ lateral to $\lambda$; and DV, $14 \mathrm{~mm}$ ventral to $\lambda$. The guide tube, manipulator, connector, anchor screws, and a small Delrin block designed to accommodate an air-puff delivery nozzle and an eyeblink sensor were secured in place with dental acrylic. After surgery, the manipulator and injection guide tube were protected with removable Delrin caps. All animals were treated with antibiotics during a $5 \mathrm{~d}$ postsurgical recovery period.

\section{Training procedures}

One week after surgery, all rabbits were first adapted to a restraint box in a sound-attenuated experiment chamber for $3 \mathrm{~d}, 30 \mathrm{~min}$ per day. Head movements were not restricted either during adaptation or during experiments. Adapted animals were conditioned in the standard delay classical conditioning paradigm until they reached $90 \%$ of conditioned responses (CRs) for at least 2 consecutive days. The conditioned stimulus (CS) was a binaural $450 \mathrm{~ms}, 80 \mathrm{~dB}$ sound pressure level, $1-\mathrm{kHz}$ tone, superimposed on a $70 \mathrm{~dB}$ white noise. As the unconditioned stimulus (US), a $100 \mathrm{~ms}, 50 \mathrm{psi}$ (at the source) air puff was applied to the left eye. The interstimulus interval was $350 \mathrm{~ms}$. The intertrial interval varied pseudorandomly from 15 to $25 \mathrm{~s}$. Rabbits had one conditioning session of 100 paired trials per day until they reached $90 \%$ of CRs for 2 consecutive days.

\section{Injection procedures}

Before each injection experiment a 33-gauge stainless-steel needle was inserted in the intracranial guide tube. The injection needle was connected to a $10 \mu \mathrm{l}$ Hamilton syringe using transparent Tygon tubing. The pressure microinjections were performed manually at a rate of $0.5 \mu \mathrm{l} /$ min. The injected volume was monitored by observing the movement of a small air bubble relative to gradation marks on the transparent tubing. During injection sessions, 40 trials of paired stimuli were applied before the injection to assure that needle insertion had no effect on CR performance. Injections were not administered if rabbits had $<85 \%$ CRs during the preinjection baseline period. NBQX (Sigma, St. Louis, MO) was dissolved in artificial CSF (aCSF) (Medina et al., 2002) and its $\mathrm{pH}$ was adjusted to $7.4 \pm 0.1$.

Functional mapping and nonwaiting experiment. To increase the yield of experiments, we first determined the effective vertical placement of NBQX injections by gradually increasing the injection depth. During the first mapping session, NBQX $(0.5 \mu \mathrm{l}, 150 \mu \mathrm{M})$ was injected at the depth of the guide tube tip. Mapping sessions consisted of 40 preinjection trials and 160 postinjection trials, which were adminis- 


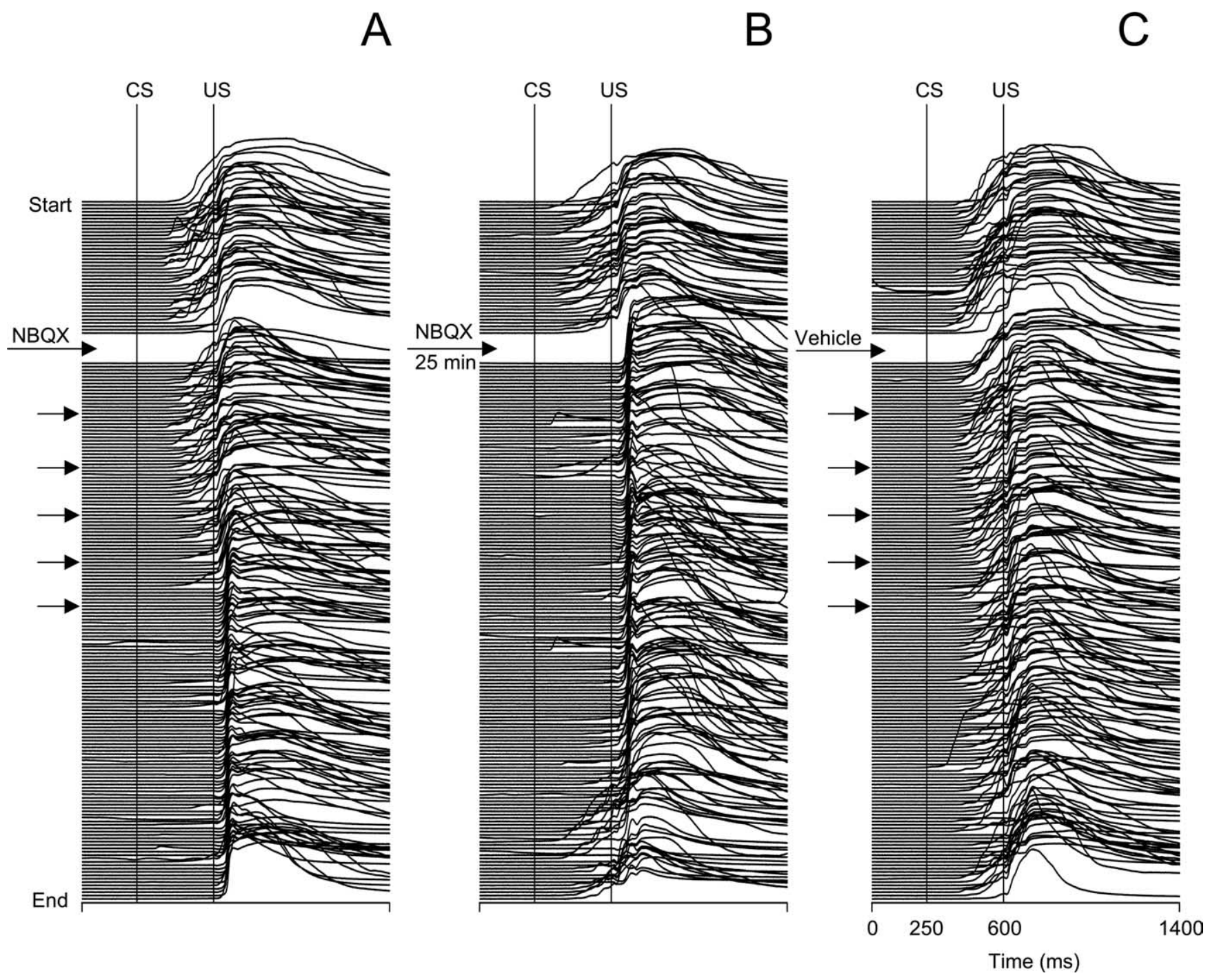

Figure 2. Individual examples from the same subject showing behavioral effects of microinjecting NBQX and vehicle (aCSF) into the I0. Each stack plot represents a complete printout of eyeblinks from a 200-trial injection experiment. The experiments start at the top, and each eyeblink trace represents one trial. The timing of injections is denoted by arrows in each stack plot. Conditioned eyeblinks are upward deflections of the signal between the vertical CS and US onset markers. $A$, Eyeblinks in an experiment where CR testing was resumed immediately after the injection of NBQX. Note that CRs were gradually abolished 23 min after NBQX. B, Stack plot of eyeblink mechanograms from an experiment in which the rabbit was injected with the same amount of drug, but the CR testing was delayed by inserting a waiting period for NBQX diffusion. In this test, CRs were absent immediately after stimuli resumed, indicating that the delayed drug effect in part $A$ was simply a function of time, most likely related to drug diffusion. Note the partial recovery of CRs as the waiting experiment continued an extra 25 min. C, Eyeblinks in the control experiment in which injections of the same amount of vehicle (aCSF) did not affect CRs.

tered immediately after the initial NBQX injection. Similar to Medina et al. (2002), additional $0.5 \mu \mathrm{l}$ injections were administered at $5 \mathrm{~min}$ intervals until an effect of the drug on CRs was observed or until a total of eight injections was reached; the total volume of NBQX ranged from $0.5-4 \mu \mathrm{l}$ among rabbits. If no effect on CR incidence was observed, the depth of injection was adjusted, progressing $0.5 \mathrm{~mm}$ deeper the next day. This daily increase of injection depth was repeated until NBQX completely abolished CRs, or until the needle reached the base of the skull. The last functional mapping session was included in the data analysis as the "nonwaiting experiment."

The waiting experiment. The next day after the nonwaiting test, all rabbits were tested in a waiting experiment, consisting of three parts. In the first part, 40 trials were delivered to assess normal preinjection $\mathrm{CR}$ performance. The second part was a waiting period designed to allow for effective drug diffusion before CS-US stimulation was resumed. During this period the same amount of NBQX was administered using the same injection schedule as in the previous nonwaiting experiment. No stimuli were presented during the waiting period and its duration was set to last 5 min longer than the time it took to abolish CRs in the nonwaiting experiment in each particular animal. After the waiting period, CR performance was tested in 160 trials.

Controls. During control experiments, a corresponding volume of vehicle (aCSF) was administered into the IO using the same injection and paired stimulation schedule as in NBQX experiments.

Injections in the IN recording group. The four rabbits in the IN recording group were repeatedly tested both in waiting and nonwaiting experiments using NBQX and aCSF injections. To capture the behavioral and neuronal recovery, we extended the postinjection observation period to a maximum of 260 trials. If the behavioral CR recovery occurred and was maintained for 40 trials (waiting experiment) or 30 trials (nonwaiting experiment), the recording session was terminated before 260 postinjection trials were completed. Once the effect of NBQX had been tested on a group of isolated single units, the microwire electrodes were advanced deeper to find an additional group of IN neurons. If new neurons were isolated, then another set of NBQX and aCSF experiments were repeated on these new units. This procedure was repeated until no more new units could be isolated, or until the NBQX injections became ineffective because of gliotic scarring around the IO injection site. Not all IN units were 


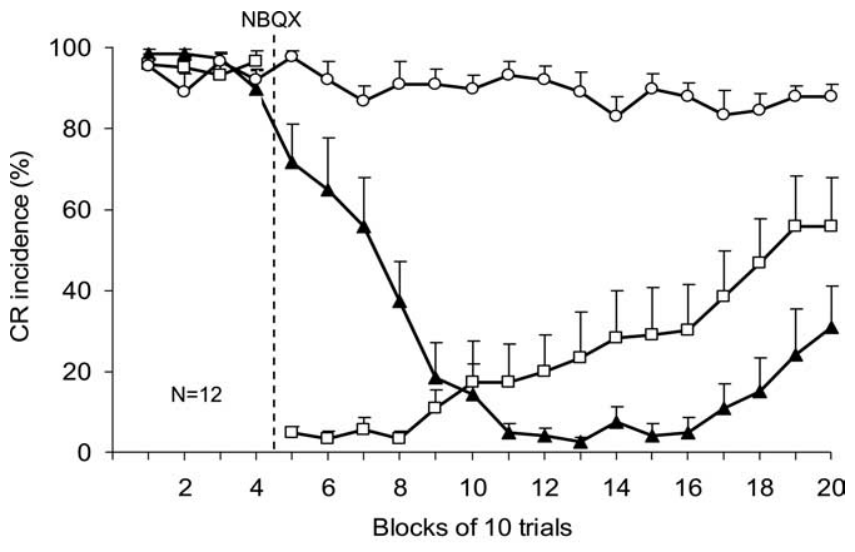

$\longrightarrow$ NBQX $\longrightarrow-\mathrm{NBQX}+$ waiting $\quad \longrightarrow-$ Control

Figure 3. Effects of NBQX on CR incidence $( \pm S E)$ in 10 injection rabbits $(n=12)$ when tested immediately after the injection $(\boldsymbol{\Lambda})$ and after the diffusion waiting period $(\square)$ are compared with those observed after the control injection of vehicle $(\bigcirc)$. The vertical dashed line denotes the onset of NBQX injections. Note that up to six blocks of trials were required to obtain complete CR abolition in the nonwaiting test, whereas CRs were immediately absent in the first postinjection block of the waiting test. Injection of vehicle (aCSF) did not affect CR incidence.

paired with control injections of aCSF because of the need to limit the number of needle insertions at the injection site, and because some units degraded or were lost before they were ready to be tested against aCSF.

\section{Data recording and analysis}

In the IO injection group, the eyeblink was recorded using a new, wide field-of-view infrared sensor (Ryan et al., 2006), which was attached to the rabbit's head implant before each experiment. This arrangement secured the constant position of the sensor relative to the eye, yielding reliable eyeblink recordings without the need for head restraint. The sensor's signal was amplified, digitized at $1 \mathrm{kHz}$ with 12 bit resolution, and displayed and stored on a custom data acquisition system. Data were acquired for $1400 \mathrm{~ms}$ in each trial, starting $250 \mathrm{~ms}$ before the CS onset. Eyeblink responses beginning between $80 \mathrm{~ms}$ after CS onset and up to the US onset were considered CRs when they exceeded the mean of the signal in the $250 \mathrm{~ms}$ baseline period by more than five SDs $(\sim 0.1 \mathrm{~mm})$. This relatively low threshold was selected to capture small responses that could be present during an incomplete drug effect or when the drug effect starts to recover. Spontaneous responses were defined as trials in which the difference between the maximum and minimum values in the baseline period exceeded $0.5 \mathrm{~mm}$. Any blink exceeding the CR threshold within $80 \mathrm{~ms}$ after CS onset was recognized as an $\alpha$ response. Trials containing spontaneous blinks or rare $\alpha$ responses were stored, but were not included in additional data analyses. Measurements of eyeblink responses were used for calculations of CR incidence per block of 10 trials in each session.

In addition to the visualization of eyeblink traces on the computer monitor, two video cameras were installed in the experiment chamber to monitor general animal behavior during experiments. One camera provided a front view of the rabbit's head and the other one, configured for infrared viewing, was positioned on the side of the trained eye. This setup proved to be invaluable for monitoring rabbit behavior continuously.

In the IN recording group, multiple single-unit signals from microwire electrodes were fed through a custom miniature 14-channel FET(field-effect transistor) based preamplifier to a multichannel differential amplifier system (model 12 Neurodata System; Grass-Telefactor, West Warwick, RI). The amplified and bandpass-filtered $(300 \mathrm{~Hz}-3 \mathrm{kHz})$ signal was digitized ( $25 \mathrm{kHz} /$ channel) using a custom data acquisition system, and was displayed and stored in $1400 \mathrm{~ms}$ epochs corresponding to individual trials. Unit discrimination was performed off-line using threshold detection followed by a cluster analysis of scatter plots of time and amplitude distances between the peak and valley of individual action potential waveforms. The discriminated data were processed using custom software in addition to a commercial data analysis package (Neuro-
Explorer; Nex Technologies, Littleton, MA). Cross-correlation analysis was performed for each unit to eliminate multiple inclusions of the same unit recorded on different wires within a bundle. Raster and perievent histograms were constructed for each unit. For cells recorded during the waiting period test, separate histograms were constructed for 30 preinjection trials, 30 trials during the waiting period while injecting, 30 trials for the postinjection period when stimulation was resumed, and 30 trials at the end of session representing recovery. The criterion for identifying the recovery period was the complete behavioral reappearance of CRs by the end of the experiment or the last 30/40 trials of a 260-trial experiment. In the latter case, the behavioral recovery could be incomplete. In each histogram, the baseline firing rate $(250 \mathrm{~ms}$ before CS onset) and the timing of significant excitatory and inhibitory changes were computed. Cell responses were considered significant if modulation of the firing rate from the CS onset until the end of the trial exceeded the mean baseline \pm tolerance limit for two consecutive $20 \mathrm{~ms}$ bins. Tolerance limits were computed to capture $95 \%$ of the baseline distribution with a probability of 0.95 .

Baseline means of individual cell histograms were pooled together within NBQX, NBQX waiting, and control experiments and then statistically analyzed. Only units that were isolated reliably throughout an experiment, as judged by the invariance of the shape and size of action potentials, were included in the data analysis.

For the statistical analysis, we used repeated measures ANOVA with the following factors: drug (three levels: drug, drug with delay, and aCSF) and time/dose (four levels: before injection, injection-no stimulation, after injection-stimulation resumed, and recovery). The repeated factor was the four 10-trial blocks for nonwaiting experiments and three 10-trial blocks for waiting experiments comprising each phase of an experiment. For the analysis of IN group cell activity, the ANOVA included an additional blocking factor (rabbit) to account for multiple cells recorded from the same animal. We generated planned contrasts from the ANOVAs to address a priori hypotheses regarding patterns of CR incidence and baseline activity of IN neurons arising from the interaction between treatments and phases of an experiment. Specifically, using groups of 10-trial blocks, we performed $1 \mathrm{df}$ contrasts between preinjection, waiting, postwaiting and recovery within and between experiments with no time delay, with time delay, and their controls. All group data are reported as mean \pm SEM. The level of statistical significance was set at $p<0.05$. All statistical analyses were performed using Statsoft (Tulsa, OK) Statistica software.

\section{Histology}

After all experiments were completed, rabbits were deeply anesthetized with a mixture of ketamine $(100 \mathrm{mg} / \mathrm{kg})$, xylazine $(12 \mathrm{mg} / \mathrm{kg})$, and acepromazine $(3 \mathrm{mg} / \mathrm{kg})$. The injection site was marked by injecting $1 \mu \mathrm{l}$ of tissue-marking dye. Anesthetized animals were transcardially perfused with $1 \mathrm{~L}$ of PBS followed by $1 \mathrm{~L}$ of fixative (10\% buffered formalin) and 1 $\mathrm{L}$ of $10 \%$ potassium ferrocyanide in $10 \%$ formalin. The potassium ferrocyanide was applied only to IN-recording rabbits, where the location of electrodes was marked by passing $10 \mu \mathrm{A}$ anodal direct current through each wire for $20 \mathrm{~s}$. Brains were removed and placed in a solution of $30 \%$ sucrose and $10 \%$ formalin. After 1 week, brains were sectioned coronally at $50 \mu \mathrm{m}$ on a freezing microtome. Sections were mounted onto gelatincoated slides, dried, and stained with either Luxol blue and neutral red (IO injection group) or with ferrocyanide hydrochloride and neutral red (IN recording group). Locations of injection sites were determined using bright field microscopy and transferred to a standardized set of coronal sections of the rabbit medulla. Locations of electrode marks were transferred to a standardized set of coronal sections of the rabbit cerebellar nuclear region.

\section{Results}

Location of injection sites and general observations

A total of 15 rabbits were implanted with an injection cannula in the IO. Three animals were not included in the data analysis because low-concentrations of NBQX $(150 \mu \mathrm{M})$ injected in the IO did not affect CR expression. Of the remaining 12 rabbits, 


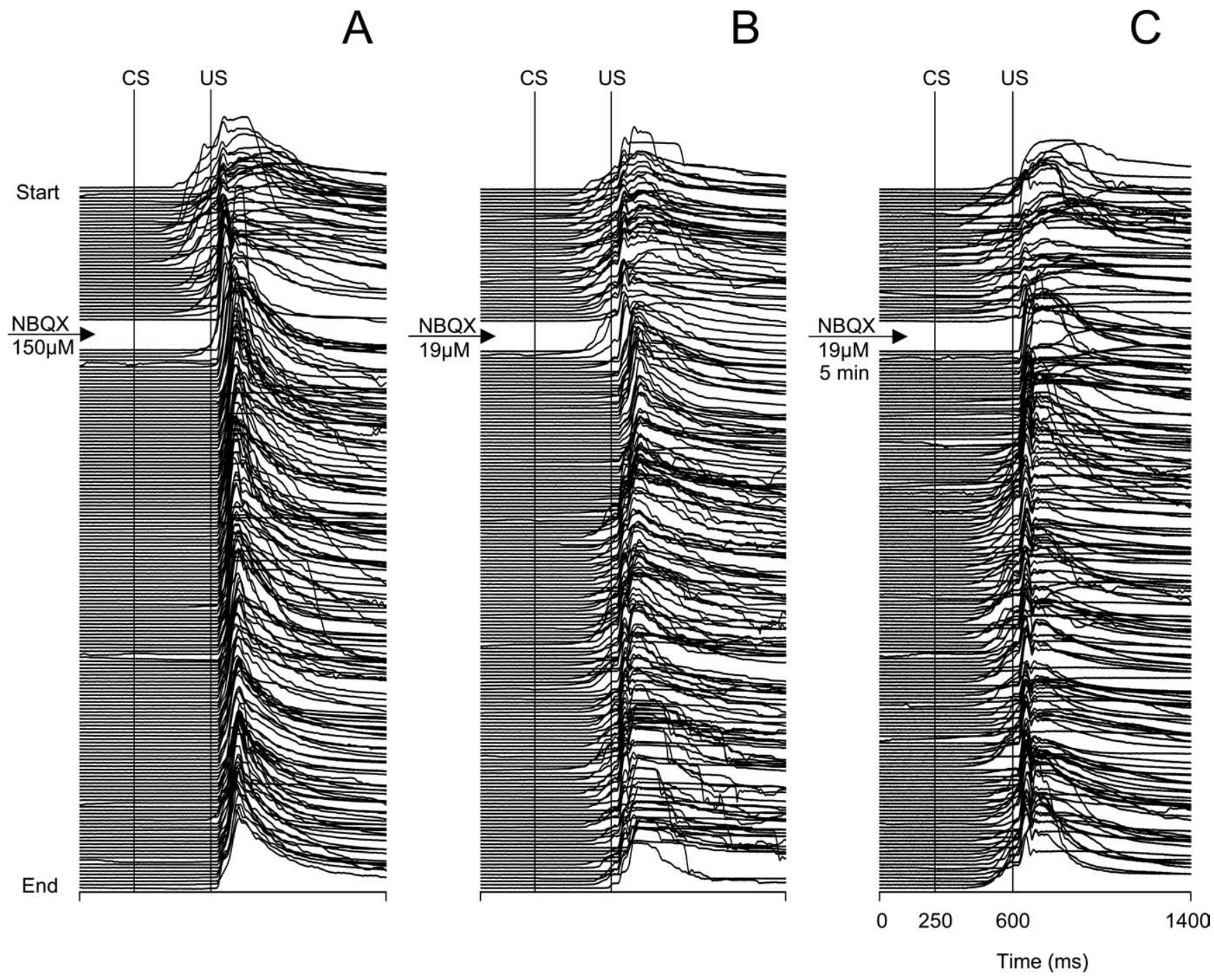

Figure 4. Stack plots of all eyeblinks recorded in three separate experiments from the same animal showing the behavioral effects of microinjecting different concentrations of NBQX in the IO. $A$, An experiment where CRs were tested immediately after an injection of $1.0 \mu$ lof NBQX (150 $\mu \mathrm{M})$. CRs were almost immediately abolished after 1 min of postinjection training. $\boldsymbol{B}$, Eyeblinks in an experiment where $1.0 \mu \mathrm{l}$ of eight times less concentrated NBQX (19 $\mu \mathrm{M})$ was injected and then an immediate test was performed. CRs were abolished after several postinjection trials, but the duration of the effect was shorter than that obtained with the higher concentration of NBQX shown in A. C, Eyeblinks in an experiment where postinjection testing of $19 \mu \mathrm{m}$ NBQX was delayed by a 5 min diffusion waiting period. Note that CRs were absent starting from the first postinjection trial, and then 10 min later they started to recover. For additional plot information, see Figure 2.

four also had recording electrodes implanted in the IN. The histological reconstruction of IO injection sites revealed that they were located in the rostral portion of the inferior olivary complex, close to the rostral part of the dorsal accessory inferior olive (Fig. 1).

All rabbits reached the $2 \mathrm{~d} 90 \%$ CR criterion in 5-12 sessions. The mean CR incidence was $91.4 \pm 0.5 \%$ in the final training session. Once effective injection sites were established through functional mapping, microinjections of NBQX reliably abolished CRs, albeit with a variable delay (for additional information, see the next two sections of Results). Unlike DGG and muscimol, which in our previous study increased tonic eyelid aperture and affected eye movement and body posture (Zbarska et al., 2007), NBQX injected to the IO did not have any visible side effects.

\section{Effect of NBQX on CR expression}

Immediate postinjection test in the nonwaiting experiment Injecting NBQX at effective injection sites abolished CR expression. Typically, rabbits exhibited high CR incidence during preinjection trials, followed by gradual CR suppression in the post-
NBQX infusion period (Fig. 2A). During the individual experiment shown in Figure $2 A, 3.0 \mu$ l of NBQX were delivered in six $0.5 \mu$ lincrements spaced $5 \mathrm{~min}$ apart. CRs were gradually abolished over the course of $\sim 23$ min after first injecting NBQX and they did not recover during the rest of the experiment. Injections of the same volume of vehicle at the same site had no effect on CR incidence (Fig. 2C).

The onset timing of CR abolition among rabbits varied from immediate to $\sim 35 \mathrm{~min}$ after injection. Group data $(n=12)$ revealed that CR incidence gradually decreased from $90.0 \pm 4.3 \%$ in the last preinjection block of 10 trials to $5.0 \pm 2.3 \%$ in the seventh postinjection block (Fig. 3). Complete or partial recovery of CRs by the end of the experiment was observed in six of 12 rabbits; during the last 10-trial block, mean CR incidence was $31.0 \pm 10.1 \%$ (Fig. 3). This decline of CR incidence contrasted with stable CR performance in control experiments before $(93 \pm 2.7 \%)$ and after $(90.3 \pm 3.9 \%)$ vehicle injections. The repeated-measures ANOVA yielded significant drug effects. Planned comparisons revealed a significant effect of $\operatorname{NBQX}\left(F_{(1,30)}=254.2, p<0.001\right)$ when contrasting overall pre- 

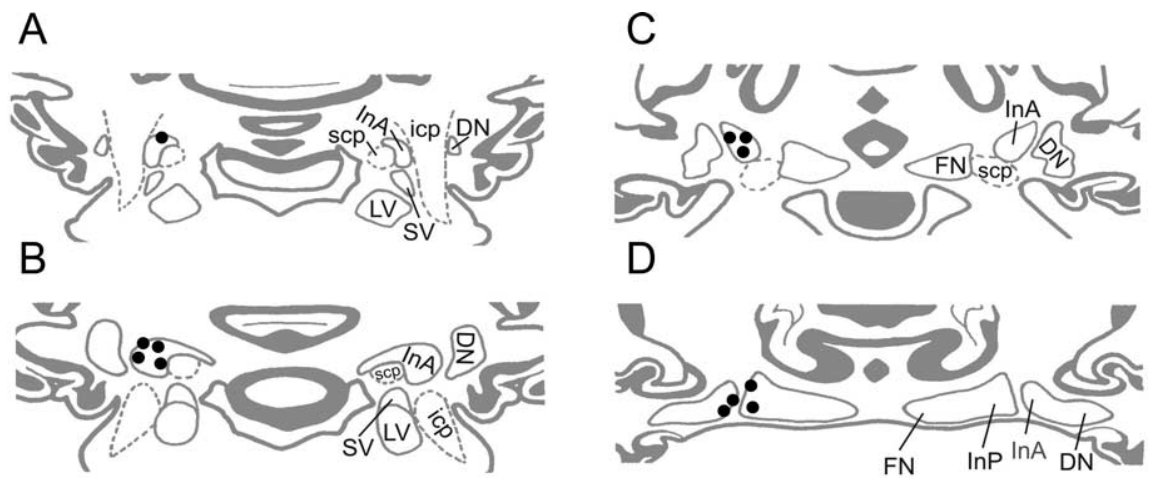

Figure 5. Reconstruction of cell recording sites in the IN. Of 12 electrode bundles in four rabbits, eight were located in the anterior IN and four at the caudal border of the anterior interposed nucleus (InA) between the dentate nucleus (DN) and posterior interposed nucleus ( $\operatorname{lnP}$ ). Their position was transferred to a set of standardized coronal sections of the rabbit cerebellar nuclear region. $\boldsymbol{A}-\boldsymbol{D}$, Sections are arranged in rostral-to-caudal order. LV, lateral vestibular nucleus; SV, superior vestibular nucleus; FN, fastigial nucleus; scp, superior cerebellar peduncle; icp, inferior cerebellar peduncle.

A

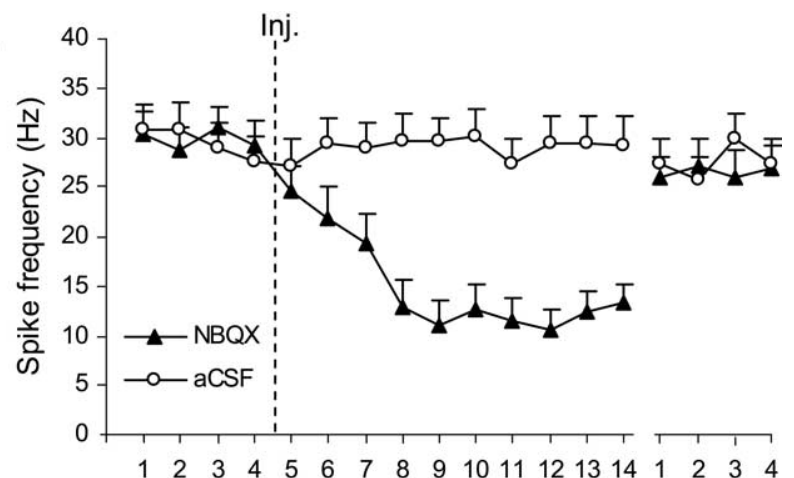

B

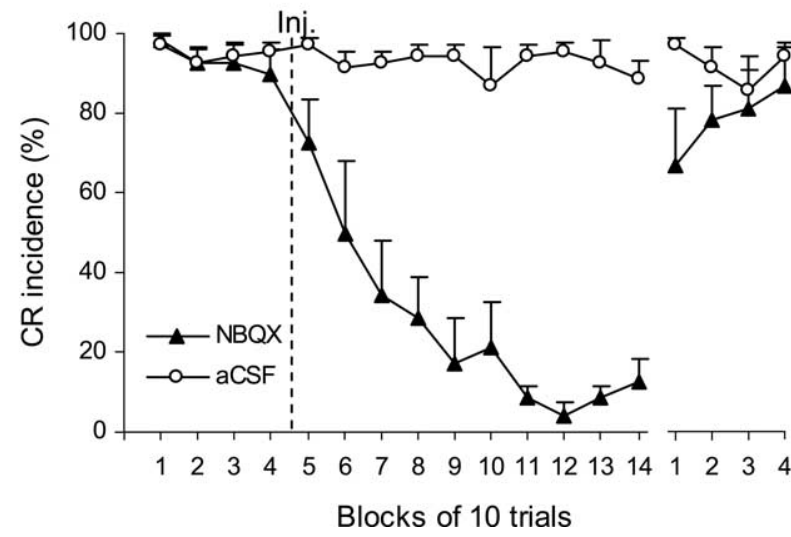

Figure 6. Group effects of NBQX on CR performance and on IN activity during the nonwaiting test. The last four blocks of trials represent the recovery period and are separated from the rest of the plot by a gap. $\boldsymbol{A}$, Effects of NBQX on mean baseline activity $( \pm S E)$ of IN cells $(n=27)$. The firing rate of IN cells gradually decreased within the first four blocks of trials after the injection of $\operatorname{NBQX}(\mathbf{\Delta})$, and it remained at slightly above $10 \mathrm{~Hz}$ for the next 60 trials. The spontaneous activity almost completely recovered during the last four blocks of the experiment. Injections of aCSF $(\bigcirc)$ had no effect on IN firing rate $(n=20)$. $\boldsymbol{B}$, Effects of NBQX $(\boldsymbol{\Delta})$ on mean CR incidence ( $\pm \mathrm{SE} ; n=7$ ) in the same set of experiments as depicted in $\boldsymbol{A}$. (Rs were gradually abolished and then partially recovered by the end of testing. This behavioral effect parallels changes in IN activity shown in $\boldsymbol{A}$. Control injections of vehicle did not affect $\mathrm{CR}$ performance.

injection and postinjection CR performances, whereas effects of vehicle were insignificant $\left(F_{(1,30)}=0.3, p=0.570\right)$.

The effect of lower concentrations of NBQX was tested on one rabbit, which in the nonwaiting experiment showed almost immediate abolition of CRs after the first of two $0.5 \mu$ linjections of NBQX (150 $\mu \mathrm{M})$ (Fig. 4A). In this animal, even an NBQX con- centration eight times lower $(19 \mu \mathrm{M})$ quickly abolished CRs with an effect lasting $\sim 50$ trials before CRs recovered (Fig. $4 B$ ). Also, CR abolition does not always require repeated injections of NBQX. We observed CR abolition after a single NBQX injection in one rabbit and after two injections in two rabbits.

\section{The waiting period test}

The waiting period test was administered to examine whether the gradual NBQXinduced abolition in the previous test was related to $\mathrm{CR}$ extinction or to some other time-dependent process, such as drug diffusion. If the gradual CR abolition represented CR extinction, then we expected that postponing the CS-US presentation after the NBQX injection should have no effect on the time course of CR suppression. This prediction was not confirmed. Figures $2 B$ and $4 C$ illustrate that CRs were absent immediately from the beginning of the postinjection test. Clearly, the NBQX-induced CR suppression did not require the presentation of the CS, which is necessary for CR extinction. In most waiting experiments, CRs partially recovered by the end of postinjection testing (Figs. 2B, 4C).

During the waiting period test, mean CR incidence precipitously declined from $96.5 \pm 2.6 \%$ in the last block of preinjection trials to $5.0 \pm 1.5 \%$ during the first 10 postwaiting trials (Fig. 3 ). The postwaiting decline in CR incidence was significant both when compared with the preinjection period $\left(F_{(1,30)}=307.7, p<0.001\right)$ and to the first block of 40 postinjection trials in the nonwaiting test $\left(F_{(1,30)}=\right.$ 36.8, $p<0.001$ ). Because of the extended period of observation during waiting period tests, CRs tended to recover in these experiments, starting from the fifth postwaiting block of trials. This recovery was observed in eight of 12 rabbits with one of them illustrated in Figure $2 \mathrm{~B}$. In the last 10 -trial block after the waiting period test, mean CR incidence in the IO injection group was $55.8 \pm 12.2 \%$. During the last 40 trials after the waiting period test, CR incidence had partially recovered to $49.2 \pm 11.8 \%$, which was significantly different from the corresponding block of trials in the nonwaiting test $\left(20.3 \pm 9.0 \% ; F_{(1,30)}=6.0 ; p=0.02\right)$.

\section{Effect of NBQX injection in the IO on neuronal activity in the IN}

Immediate postinjection test

The histological reconstruction performed in the four IN recording rabbits revealed injection sites located close to the rostral portion of the dorsal accessory olive (Fig. 1). All recording sites were located in the IN, with the majority of electrodes in the anterior IN (Fig. 5). In total, 27 neurons were recorded during NBQX injections and 20 neurons during injections of vehicle, all in the nonwaiting experiment. Single-unit recordings revealed that the gradual CR abolition induced by NBQX coincided with the gradual suppression of spontaneous firing rates of IN cells (Figs. 6A,B). In this NBQX cell population, the mean baseline firing rate decreased significantly, first from $29.8 \pm 2.3 \mathrm{~Hz}$ preinjection to $19.2 \pm 3.0 \mathrm{~Hz}$ by the third postinjection block of 10 trials, and then to $11.0 \pm 2.5 \mathrm{~Hz}$ by the fifth postinjection block (Fig. 6A) (blocks $1-4$ vs $5-14 ; F_{(1,42)}=70.2 ; p<0.001$ ). The baseline firing rate markedly recovered during the last 40 trials (blocks 5-14 vs $15-18 ; F_{(1,42)}=51.8, p<0.001$ ), and it almost reached its preinjection level of activity (blocks $1-4$ vs $15-18$; 
$\left.F_{(1,42)}=6.0, p=0.018\right)$. In contrast, the mean firing rate during control experiments remained stable after vehicle-only injections (Fig. 6A) (blocks $1-4$ vs 5-14; $\left.F_{(1,42)}=0.030 ; p=0.864\right)$. The time gap between the last 10-trial block of postinjection trials (Fig. 6, Block 14) and the first block of the recovery period varied from 7 to 27 min (20-80 trials).

The NBQX-induced decrease of IN neuronal activity coincided with a gradual decline in mean CR incidence from $93.6 \pm$ $3.9 \%$ preinjection to $34.3 \pm 13.8 \%$ by the third postinjection block, and then to $4.29 \pm 3.0 \%$ by the eleventh block (Fig. $6 B)$ (blocks $1-4$ vs $5-14 ; F_{(1,8)}=495.3$; $p<0.001)$. Likewise, a behavioral recovery, which paralleled the recovery of neuronal activity during the last 40 trials, was significant when compared with blocks $11-14\left(F_{(1,8)}=245.6, p<0.001\right)$, but it was incomplete relative to the preinjection level $\left(F_{(1,8)}=40.0, p<0.001\right)$. Control injections of aCSF in the IO had no effect on CR incidence which was $95.0 \pm 2.6 \%$ and $92.3 \pm 3.8 \%$ before and after vehicle injections correspondingly (Fig. 6B).

\section{The waiting period test}

Inserting a waiting period between the NBQX injection and behavioral testing provided a unique opportunity to measure IN activity at this time. As illustrated in an individual example, IN neurons exhibited a strong excitatory response to the CS before the onset of the US and a combination of excitatory and inhibitory responses to the US (Fig. $7 A, B$ ). The NBQX injection in the IO of this rabbit almost immediately severely suppressed the firing rate of the IN unit during the no-stimulation period (Figs. $7 A, C$ ). When stimulation was resumed, behavioral CRs were absent. At the same time, the firing rate of this cell remained inhibited and its modulation was altered. The excitatory response to the CS dramatically decreased and the excitatory response to the US became more prominent, albeit shorter-lasting (Figs. $7 A, D$ ). Toward the end of the session the behavioral effect gradually recovered (Fig. 7A), accompanied by a partial recovery of the neuronal firing rate and modulation (Fig. $7 A, E)$.

In total, 88 neurons were successfully held and recorded during the NBQX waiting period test and 32 neurons in vehicle injection controls. Among the 88 NBQX neurons, 79 cells exhibited a significant decrease in baseline activity during the waiting period when compared with the preinjection level. Of the nine remaining neurons in this group, eight did not change their activity and one neuron significantly increased its firing rate. The mean baseline firing rate of NBQX neurons $(n=88)$ decreased by more than half from

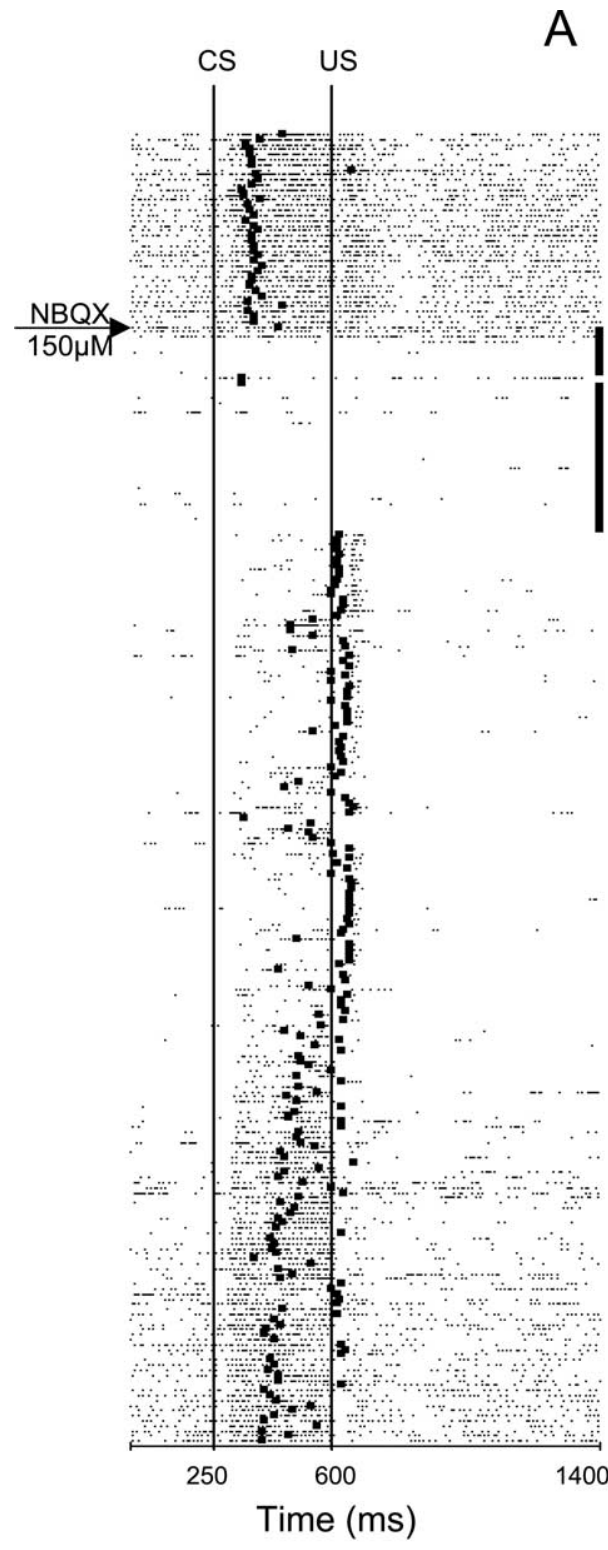

$A$
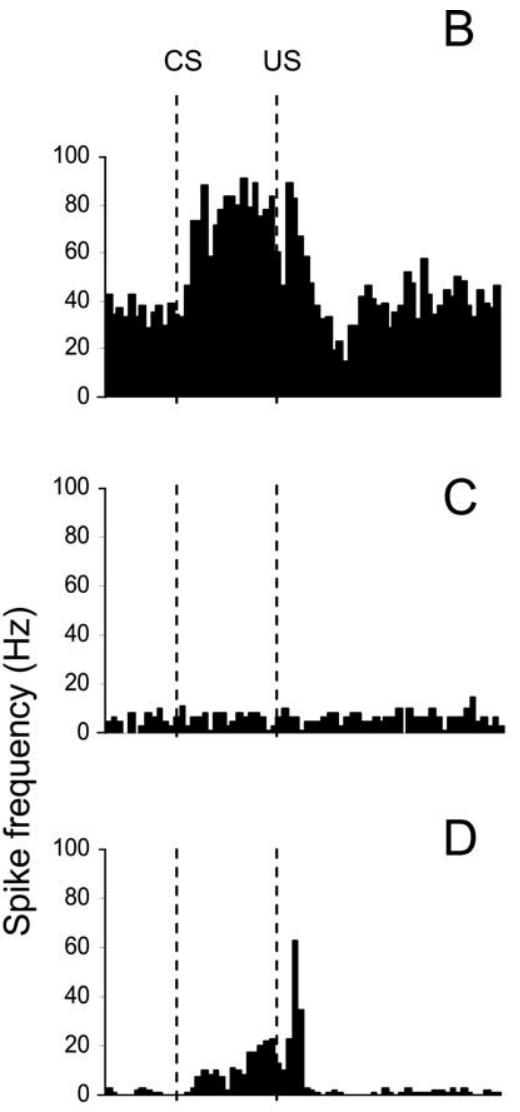

Figure 7. An example from a waiting period test of the parallel effects of NBQX on CR performance and on the activity of a task-modulated IN cell. This experiment consisted of 260 trials with the two $0.5 \mu$ I NBQX injections administered during the 40-trial no-stimulation period that began immediately after 40 preinjection trials. A, Raster plot of IN cell activity during the same experiment. The experiment starts at the top with each row representing one trial, and each dot marking the occurrence of an action potential. The black square on each row corresponds to the onset of the eyeblink in that particular trial. The 40 black squares at the ends of rows correspond to the no-stimulation waiting period. This cell responded with excitation during the CS-US interval followed by a combined excitatory/inhibitory response to the US. Shortly after the first NBQX injection, the firing rate of this cell's activity precipitously declined. When stimulation was resumed, CRs were abolished immediately, baseline activity remained suppressed, and modulation during the CS-US interval was severely reduced whereas the relative excitatory modulation to the US became more distinct. The neuronal activity gradually recovered toward the end of the experiment in parallel with the recovery of behavioral CRs. $\boldsymbol{B}-\boldsymbol{E}$, Peristimulus histograms of the same IN unit constructed for 40 trials before the injection $(\boldsymbol{B})$, for 40 postinjection waiting trials when stimulation was paused $(\boldsymbol{C})$, for 40 postwaiting period trials when stimulation was resumed $(\boldsymbol{D})$, and for the last 40 trials of the experiment (E). Bin width for histograms in $\boldsymbol{B}-\boldsymbol{E}$ is $20 \mathrm{~ms}$. CS, Onset of conditioned stimulus; US, onset of unconditioned stimulus.
$28.1 \pm 1.5 \mathrm{~Hz}$ preinjection to $13.1 \pm 1.3 \mathrm{~Hz}$ by the end of waiting period (Fig. $8 A$ ) (blocks $1-3$ vs $4-6 ; F_{(1,118)}=77.0 ; p<0.001$ ). When stimulation was resumed, the mean baseline firing rate decreased further to $11.4 \pm 1.3 \mathrm{~Hz}$ (blocks $1-3$ vs $7-9 ; F_{(1,118)}=$ 104.4, $p<0.001)$. Recovery of the baseline firing rate occurred during the last 30 trials (blocks $10-12$ vs $4-9 ; F_{(1,118)}=66.0, p<$ $0.001)$, but it was incomplete relative to the preinjection activity 


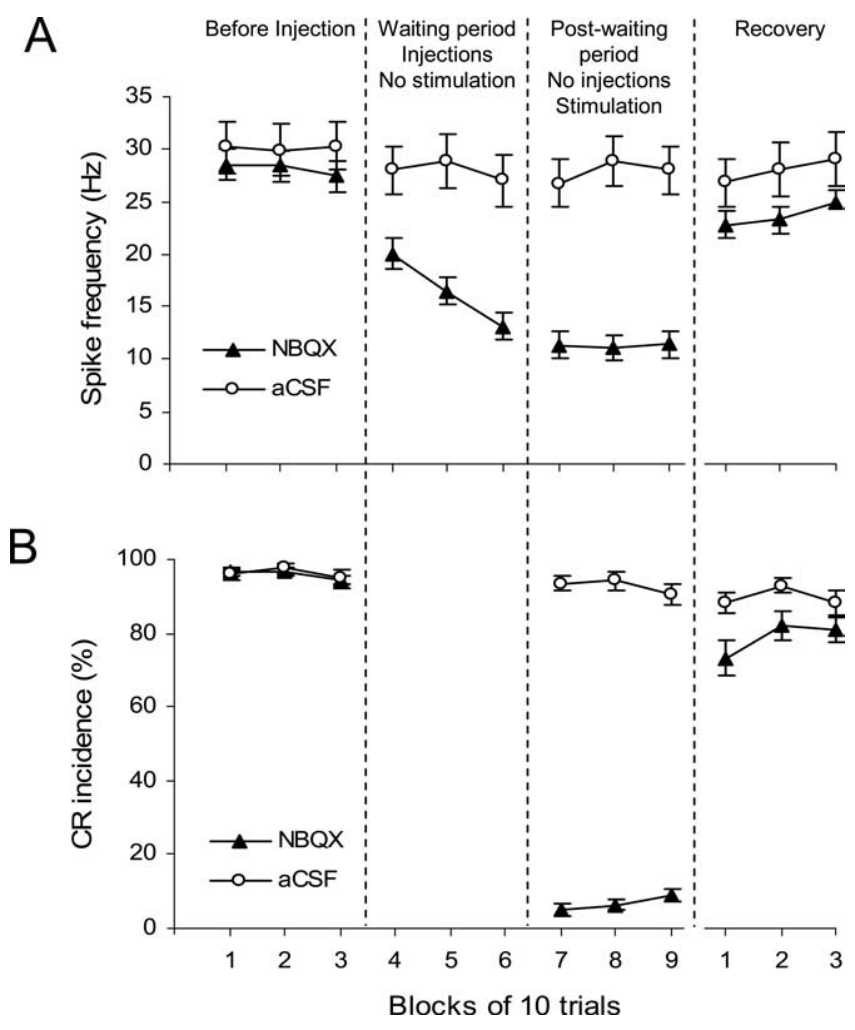

Figure 8. Group effects of $\mathrm{NBQX}$ on CR performance and on IN activity during the waiting test. Each period of the experiment is represented by three consecutive blocks of 10 trials: before injection, no-stimulation waiting period, postwaiting period with stimulation, and recovery. Periods are separated by vertical dashed lines. If the waiting period was longer than 30 trials, then the last 30 trials before stimulation was resumed were included in the plot. $A$, Effects of $\mathrm{NBQX}(\mathbf{\Delta})$ on mean baseline activity ( $\pm \mathrm{SE} ; n=88$ ) of IN cells. The baseline firing rate of IN cells gradually decreased during the waiting period, it remained low when stimulation was resumed and it partially recovered during the last three blocks of the experiment. Injecting aCSF $(O)$ had no significant effect on IN firing rate $(n=36)$. $\boldsymbol{B}$, Effects of NBQX $(\boldsymbol{\Delta})$ on mean $C R$ incidence $( \pm \mathrm{SE} ; n=32)$ in the same set of experiments as depicted in $\boldsymbol{A}$. CRs were completely abolished when stimulation was resumed and then partially recovered by the end of testing. This behavioral effect parallels changes in IN activity shown in $\boldsymbol{A}$. Control injections of vehicle $(O)$ did not affect CR performance.

(blocks $1-3$ vs $\left.10-12 ; F_{(1,118)}=11.3, p=0.001\right)$. The time gap between the last 10-trial block of postinjection trials (Fig. 8, block 9) and the first block of the recovery period varied from 10 to 43 min (30-130 trials). The firing rate of IN neurons was not affected by control injections of vehicle, as the mean firing rate remained stable before $(30.0 \pm 2.4 \%)$ and after $(27.3 \pm 2.3 \%)$ injections (Fig. 8A) (blocks $1-3$ vs $7-9 ; F_{(1,118)}=0.736 ; p=$ $0.393)$.

When stimulation was resumed after the waiting period, CRs were absent at the beginning of the postwaiting test (Fig. $8 \mathrm{~B}$ ). The mean CR incidence decreased from $94.3 \pm 1.3 \%$ in the last block of preinjection trials to $5.0 \pm 1.6 \%$ during the first 10 postwaiting trials (blocks $1-3$ vs $7-9 ; F_{(1,43)}=3165.6, p<0.001$ ). Similar to the neuronal activity, partial recovery of CR incidence was observed in the last 30 trials of the recording session (Fig. $8 \mathrm{~B}$ ), which was significant when compared with postwaiting trials $\left(F_{(1,43)}=\right.$ $341.4, p<0.001)$, but was incomplete relative to the preinjection level $\left(F_{(1,43)}=24.4, p<0.001\right)$. The control injections of aCSF did not affect $C R$ incidence (Fig. $8 B$ ) (blocks $1-3$ vs $7-9 ; F_{(1,43)}=$ 3.423; $p=0.071$ ).

To analyze changes in modulation of IN neurons, all cells from NBQX waiting experiments $(n=88)$ were subdivided into three subgroups based on their pattern of significant modulation in the CS-US interval before injections. Our minimum threshold criterion for modulated activity was two consecutive $20 \mathrm{~ms}$ bins exceeding the upper or lower tolerance limits that were calculated from the first $250 \mathrm{~ms}$ of preinjection peristimulus histograms. As a result, 16 neurons exhibited predominantly excitatory modulation, 12 neurons were largely inhibited and 60 neurons were not modulated. However, 20 of the "nonmodulated" cells exhibited a short-latency, short-lasting $(20 \mathrm{~ms})$ excitatory response to the CS.

In general, the spontaneous activity of all cell types decreased during the waiting period (Figs. 9B, $F, J$ ). When CS-US stimulation was resumed, the modulation of both excitatory and inhibitory cells was also reduced, but not completely abolished (Figs. $9 C, G)$. These changes recovered toward the end of the experiment (Figs. 9D, H,L). The most affected modulation components were the prolonged excitation and inhibition in the CS-US interval (Fig. 9, compare $A, C$, and $E, G$ ). Interestingly, short-latency excitatory responses to the CS and US proved to be relatively resistant to the NBQX effect. Because the IO has been proposed to provide the intermediate cerebellum with the US information, it was surprising that relative responses to the US were not dramatically reduced. Unexpectedly, the responses to the US became more prominent in all three cell types (Figs. 9C, $G, K$ ). In contrast to NBQX experiments, control injections of the vehicle in the IO had no significant effects on baseline activity or modulation (Fig. 9M-P).

Because the population superhistograms (Fig. 9) could have means disproportionately affected by the depth of modulation of individual cells, we also constructed binary histograms. By depicting cumulative frequencies of significant excitatory and inhibitory modulation within each $20 \mathrm{~ms}$ bin, this plot (Fig. 10) disregards amplitude of modulation by providing information about the percentage of significantly modulated cells. This analysis showed similar results as described above. Specifically, the incidence of prolonged inhibition and excitation in the CS-US interval decreased after the NBQX injection (Figs. 10, compare $A$, $B)$. Interestingly, only inhibitory parts of this response component recovered well by the end of the experiment (Fig. 10, compare $B, C)$. Similar to effects seen in Figure 9, the frequency of short-latency responses to the CS was not reduced in the postinjection test. Remarkably, injecting NBQX in the IO increased the frequency of both short- and long-latency excitatory responses to the US (Fig. 10, compare $A, B$ ) and this effect recovered by the end of the experiment (Fig. 10C).

\section{Discussion}

The present study demonstrated that injections of the AMPA/ kainate receptor antagonist, NBQX, in rostral parts of the inferior olive abolish the expression of eyeblink CRs. This NBQXinduced CR suppression exhibited variably delayed onset timing, ranging from an immediate effect to $35 \mathrm{~min}$ postinjection. Simultaneous recordings of IN single-unit activity revealed that CR abolition was associated with decreased tonic activity and changes in evoked neuronal responses in deep cerebellar nuclei. The waiting test, in which CS and US presentations were delayed to permit drug diffusion, showed that these effects were simply a function of time and therefore did not require postinjection presentations of stimuli.

Involvement of the IO in expression of CRs: tonic dysfunction versus cerebellar learning hypothesis

The expression of eyeblink CRs in the rabbit depends critically on the intermediate cerebellum. The IO, which is the exclusive 
source of cerebellar climbing fibers, is a pivotal component of cerebellar eyeblinkrelated circuits. A subdivision of the IO, the dorsal accessory olive, receives information about periocular stimulation from sensory trigeminal nuclei (Walberg, 1982; Gellman et al., 1983; Huerta et al., 1983) and transmits this US signal to the intermediate cerebellum. Previous lesion and inactivation studies (Yeo et al., 1986; Welsh and Harvey, 1998) demonstrated that blocking the IO input to the cerebellum abolishes CRs immediately after the experimental intervention. Authors of these behavioral studies speculated that a tonic dysfunction of the cerebellar circuit could explain this effect. Specifically, they suggested that CR deficits were caused by a nonspecific tonic suppression of activity in cerebellar nuclei that is known to be associated with IO lesions/inactivations (Benedetti et al., 1983; Zbarska et al., 2007). These findings were challenged by reports that lesioning (McCormick et al., 1985) or inactivating (Medina et al., 2002) the IO produces not an immediate, but gradual, extinction-like suppression of CRs. These findings were interpreted in terms of the cerebellar learning hypothesis, which suggests that the IO input is required for the maintenance of memory traces in the cerebellum (Thompson et al., 1998). According to this concept, blocking the IO gradually weakens cerebellar responses to the CS, resulting in CR extinction. Resolving these conflicting inferences from behavioral studies requires measurements of cerebellar neuronal activity during IO manipulations. To address this challenging issue, we applied our method of long-term single-unit recording to experiments involving IO pharmacological manipulations in trained rabbits.

The behavioral component of the present study clearly supports the tonic dysfunction hypothesis. Blocking the IO's AMPA/ kainate glutamate receptors with NBQX abolished CRs either almost immediately, or with a short delay. This rate of NBQXinduced CR suppression was appreciably faster than the rate of normal behavioral extinction previously observed in our laboratory (Nilaweera et al., 2005). In the waiting period test, CRs were abolished immediately, starting from the first trial of resumed CS and US presentations. These findings are inconsistent with a cerebellar learning hypothesis which postulates that NBQX-induced CR "extinction" follows the presentation of paired stimuli and should have a rate comparable to normal behavioral extinction (Medina et al., 2002).

Because presentation of stimuli was not required to observe CR abolition, we suggest that some time-dependent process, such as drug diffusion to relevant parts of the IO complex, explains the delayed cases of the drug effect. The drug diffusion explanation is consistent with the histological reconstruction of our injection sites. First of all, it is unlikely that CR suppression was caused by the drug spreading to some other eyeblink-related target outside of the IO (Hiraoka and Shimamura, 1977; Holstege, 1990). Injec-

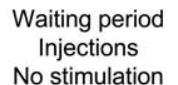
Post-waiting period No injections

Stimulation resumed

A
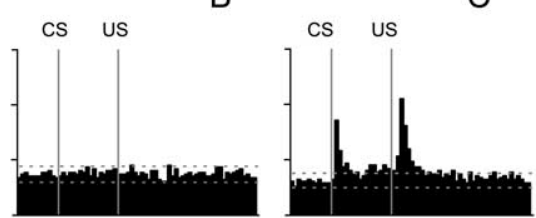

CS US

$\mathrm{D}$

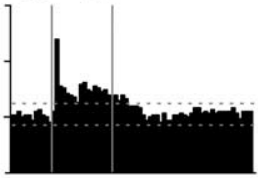

$\mathrm{F}$

G
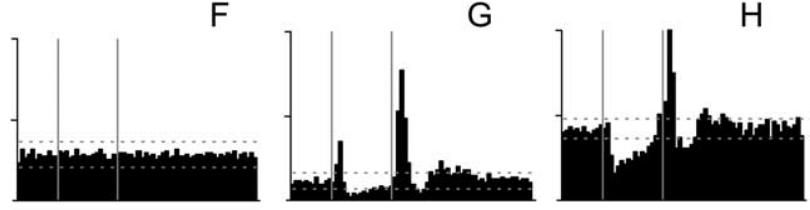

$\mathrm{H}$
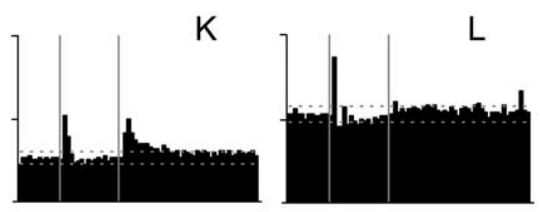

M

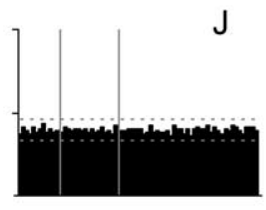

N
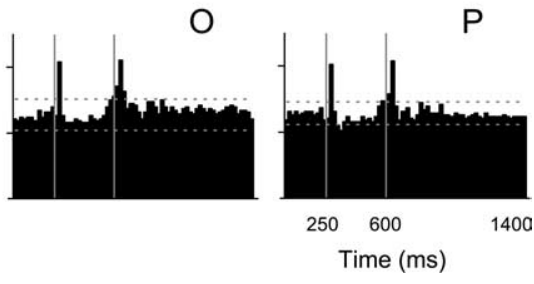

P

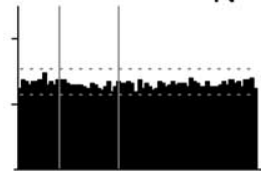

$\mathrm{O}$

Figure 9. Effects of NBQX and aCSF injections on cell activity modulation. Mean peristimulus histograms are arranged in rows corresponding to cell types and in columns representing the activity before injection, during the no stimulation waiting period,

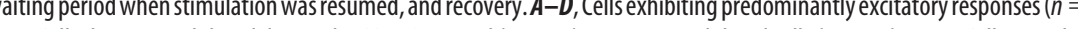
ms. Horizontal lines in each histogram represent tolerance limits. For a more detailed description, see Results, Effect of NBQX injection in the 10 on neuronal activity in the IN.

tions of NBQX dorsal to the IO made before the last mapping experiment had no effect on CRs. Also, the fastest effects were observed in animals with injection sites closest to the rostralmedial pole of the DAO, which is known to receive somatosensory information from the contralateral facial region (Gellman et al., 1983).

The tonic dysfunction hypothesis is strongly supported by our recordings of IN single-unit activity. The gradual reduction of CRs is well correlated with a gradual inhibition of the spontaneous firing rate of IN neurons in immediate drug tests. The waiting experiments clearly dissociated these processes because the IN firing rate declined during the waiting period when rabbits were not stimulated. When the stimulation resumed, CRs were immediately absent on the background of already suppressed IN activity. This stimulation-independent and NBQX-induced suppression of IN firing rate is consistent with previous reports of the tonic effects of blocking IO input to the cerebellum (Benedetti et al., 1983; Bengtsson et al., 2004). It appears that NBQX downregulated the firing rate of the $\mathrm{IO}$ and this upregulated the activity of Purkinje cells in the cerebellar cortex (Batini et al., 1985; Lang, 2001; Bengtsson et al., 2004). The increased activity of these inhibitory cells then suppressed activity of IN neurons, as shown by our measurements. Because sustained inhibition of IN neurons suppresses CR expression (Aksenov et al., 2004), we presume that the NBQX-triggered tonic shifts in the activity of cerebellar neu- 


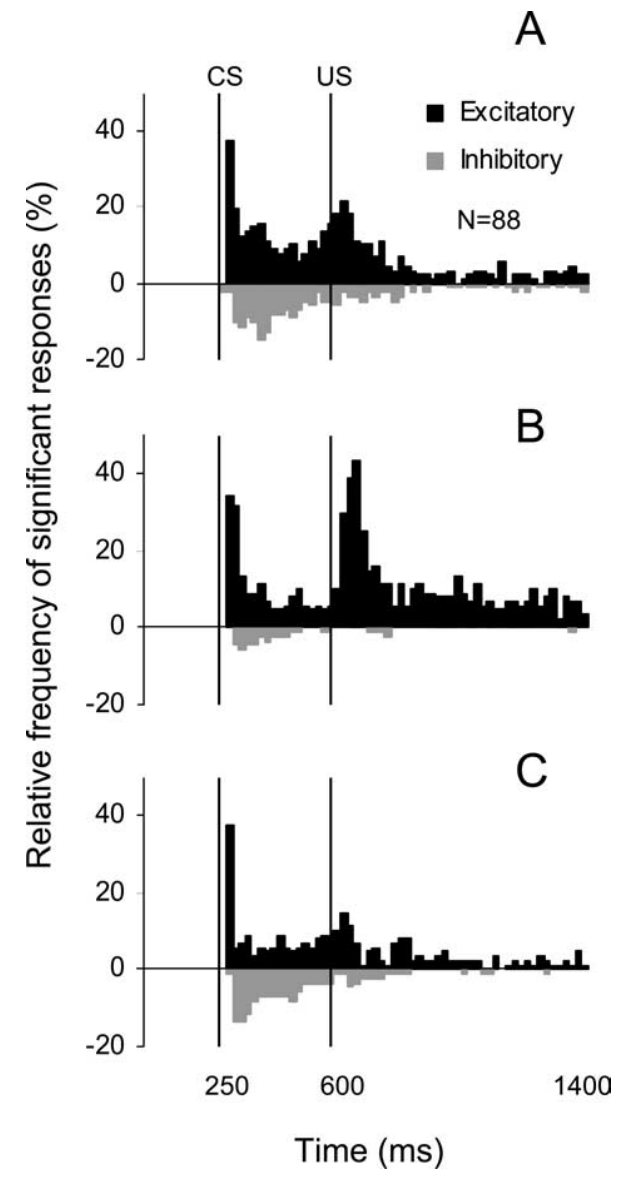

Figure 10. $\quad A-C$, Frequency histograms of the incidence of significant excitatory (black bars) and inhibitory (gray bars) responses in the population of 88 cells recorded during the NBQX waiting experiments ( $\boldsymbol{A}$, before injection; $\boldsymbol{B}$, after injection when stimulation was resumed; $\boldsymbol{C}$, during last 30 trials of experiments). The fraction of cells exhibiting long-latency excitatory or inhibitory responses in the CS-US interval decreased after the NBQX application. Also, the incidence of short-latency excitation to the $C S$ remained unchanged and the incidence of excitatory responses to the US increased after NBQX. These effects tended to recover toward the end of experiments.

rons are either partly or completely responsible for the observed $\mathrm{CR}$ deficit. Interestingly, even though the NBQX-induced suppression of IN activity was sufficient to prevent CR expression, it was smaller than what we reported in DGG injection experiments (Zbarska et al., 2007). Because DGG blocks AMPA/kainate and also NMDA receptors, it appears that NMDA receptors participate in the regulation of IO firing rates (Placantonakis and Welsh, 2001).

Although the tonic activity of some IN neurons was completely suppressed, most cells continued to fire but at significantly decreased rates. It is not clear whether the residual presence of tonic modulated activity in the IN is related to an incomplete block of AMPA/kainate receptors in areas of the IO that project to our recording sites. Exploring this scenario would require injecting excess amounts of NBQX. We have not yet performed this test because interpreting the results of a more complete block could be confounded by excess drug spreading to other parts of eyeblink circuits, which would have required additional controls. Similar to changes in spontaneous firing rates, the depth of response modulation and its incidence were reduced, but not completely eliminated. The most reduced response components were longer-latency (>60 ms) excitatory and inhibitory responses in the CS-US interval. However, short-latency responses to the CS remained relatively stable and the incidence of responses to the US actually increased. The increased responses to the US are surprising because the $\mathrm{IO}$ is presumed to be a major source for the US signal. It is likely that after IO inactivation with NBQX, information about the US reached the cerebellum through trigeminocerebellar mossy fiber projections that are known to convey somatosensory information from facial areas (Woolston et al., 1981; Kassel et al., 1984; Ikeda and Matsushita, 1992). This finding raises the possibility of functionally significant, extraolivary US inputs to eyeblink-related IN neurons that may need to be incorporated in the models of eyeblink conditioning.

In summary, we propose that the NBQX-induced abolition of CRs was most likely caused by the stimulus-independent suppression of IN's tonic rate and of its neuronal responses in the CS-US interval. This conclusion contradicts Medina et al. (2002), who reported stimulation-dependent CR extinction during continuous injections of NBQX in the IO. We could not replicate this result despite using the same drug concentration and a very similar experimental setup. On the contrary, smaller amounts of NBQX in a larger group of rabbits invariably abolished CRs in a stimulation-independent manner. In one of our animals, a much smaller amount of NBQX (eight-times smaller concentration) also yielded CR abolition. Two aspects of the study by Medina et al. (2002) could have contributed to this difference. First of all, their study had a complex design with animals being subjected to infusions of picrotoxin and vehicle and to repeated extinction and CR re-acquisition sessions before their NBQX tests. Although unlikely, it cannot be excluded that these procedures altered the physiology of underlying circuits in a manner making them resistant to NBQX effects on cerebellar tonic activity. Another possibility is that repeated injections in Medina et al.'s study induced the formation of glial scarring that progressively degraded the effective drug diffusion, yielding more delayed effects in their waiting test. This is a common problem in studies that involve repeated injections at the same site. Anticipating this effect, we added an additional $5 \mathrm{~min}$ to the waiting period test in the present study. However, independent of the resolution of this conflict, our data demonstrate that NBQX injected in the IO abolishes CRs not because of unlearning, but by rendering cerebellar circuits dysfunctional.

\section{Implications for future studies}

Although this study supports the tonic dysfunction hypothesis and challenges certain tenets of the cerebellar learning hypothesis, it should be emphasized that these hypotheses are not mutually exclusive. The IO possibly could provide the intermediate cerebellum with the "teaching" US input as postulated in the cerebellar learning hypothesis while at the same time regulating tonic activity in the cerebellum. This possible dual role of the IO has important consequences for developing experimental strategies in addressing IO participation in eyeblink conditioning. New methods will have to be developed to block IO responses to the US without significantly affecting its spontaneous firing rate. The important contribution of this study is its demonstration that blocking AMPA/kainate receptors in the IO does not achieve this desirable effect. An equally important implication is that the use of electrophysiological recordings performed simultaneously with pharmacological manipulations and behavioral assessment of CRs is essential for deciphering the mechanism responsible for changes observed after cerebellar manipulations. 


\section{References}

Aksenov D, Serdyukova N, Irwin K, Bracha V (2004) GABA neurotransmission in the cerebellar interposed nuclei: involvement in classically conditioned eyeblinks and neuronal activity. J Neurophysiol 91:719-727.

Batini C, Billard JM, Daniel H (1985) Long-term modification of cerebellar inhibition after inferior olive degeneration. Exp Brain Res 59:404-409.

Benedetti F, Montarolo PG, Strata P, Tempia F (1983) Inferior olive inactivation decreases the excitability of the intracerebellar and lateral nuclei in the rat. J Physiol (Lond) 340:195-208.

Bengtsson F, Svensson P, Hesslow G (2004) Feedback control of Purkinje cell activity by the cerebello-olivary pathway. Eur J Neurosci 20:2999-3005.

Bracha V, Webster ML, Winters NK, Irwin KB, Bloedel JR (1994) Effects of muscimol inactivation of the cerebellar interposed-dentate nuclear complex on the performance of the nictitating membrane response. Exp Brain Res 100:453-468.

Gellman R, Houk JC, Gibson AR (1983) Somatosensory properties of the inferior olive of the cat. J Comp Neurol 215:228-243.

Hiraoka M, Shimamura M (1977) Neural mechanisms of the corneal blinking reflex in cats. Brain Res 125:265-275

Holstege G (1990) Neuronal organization of the blink reflex. In: The human nervous system (Paxinos G, ed), pp 287-296. San Diego: Academic.

Huerta MF, Frankfurter A, Harting JK (1983) Studies of the principal sensory and spinal trigeminal nuclei of the rat: projections to the superior colliculus, inferior olive, and cerebellum. J Comp Neurol 220:147-167.

Ikeda M, Matsushita M (1992) Trigeminocerebellar projections to the posterior lobe in the cat, as studied by anterograde transport of wheat germ agglutinin-horseradish peroxidase. J Comp Neurol 316:221-237.

Kassel J, Shambes GM, Welker W (1984) Fractured cutaneous projections to the granule cell layer of the posterior cerebellar hemisphere of the domestic cat. J Comp Neurol 225:458-468.

Krupa DJ, Thompson RF (1997) Reversible inactivation of the cerebellar interpositus nucleus completely prevents acquisition of the classically conditioned eye-blink response. Learn Mem 3:545-556.

Lang EJ (2001) Organization of olivocerebellar activity in the absence of excitatory glutamatergic input. J Neurosci 21:1663-1675.

Marr D (1969) A theory of cerebellar cortex. J Physiol (Lond) 202:437-470.

McCormick DA, Thompson RF (1984) Cerebellum: essential involvement in the classically conditioned eyelid response. Science 223:296-299.

McCormick DA, Steinmetz JE, Thompson RF (1985) Lesions of the inferior olivary complex cause extinction of the classically conditioned eyeblink response. Brain Res 359:120-130.
Medina JF, Nores WL, Mauk MD (2002) Inhibition of climbing fibres is a signal for the extinction of conditioned eyelid responses. Nature 416:330-333.

Mintz M, Lavond DG, Zhang AA, Yun Y, Thompson RF (1994) Unilateral inferior olive NMDA lesion leads to unilateral deficit in acquisition and retention of eyelid classical conditioning. Behav Neural Biol 61:218-224.

Montarolo PG, Palestini M, Strata P (1982) The inhibitory effect of the olivocerebellar input on the cerebellar Purkinje cells in the rat. J Physiol (Lond) 332:187-202

Nilaweera WU, Zenitsky GD, Bracha V (2005) Inactivation of the brachium conjunctivum prevents extinction of classically conditioned eyeblinks. Brain Res 1045:175-184.

Placantonakis D, Welsh J (2001) Two distinct oscillatory states determined by the NMDA receptor in rat inferior olive. J Physiol (Lond) 534:123-140.

Ryan SB, Detweiler KL, Holland KH, Hord MA, Bracha V (2006) A longrange, wide field-of-view infrared eyeblink detector. J Neurosci Methods $152: 74-82$.

Thompson RF (1986) The neurobiology of learning and memory. Science 233:941-947.

Thompson RF, Thompson JK, Kim JJ, Krupa DJ, Shinkman PG (1998) The nature of reinforcement in cerebellar learning. Neurobiol Learn Mem 70:150-176.

Walberg F (1982) The trigemino-olivary projection in the cat as studied with retrograde transport of horseradish peroxidase. Exp Brain Res 45:101-107.

Welsh JP, Harvey JA (1989) Cerebellar lesions and the nictitating membrane reflex: performance deficits of the conditioned and unconditioned response. J Neurosci 9:299-311.

Welsh JP, Harvey JA (1998) Acute inactivation of the inferior olive blocks associative learning. Eur J Neurosci 10:3321-3332.

Woolston DC, Kassel J, Gibson JM (1981) Trigeminocerebellar mossy fiber branching to granule cell layer patches in the rat cerebellum. Brain Res 209:255-269.

Yeo CH, Hardiman MJ, Glickstein M (1985) Classical conditioning of the nictitating membrane response of the rabbit. I. Lesions of the cerebellar nuclei. Exp Brain Res 60:87-98.

Yeo CH, Hardiman MJ, Glickstein M (1986) Classical conditioning of the nictitating membrane response of the rabbit. IV. Lesions of the inferior olive. Exp Brain Res 63:81-92.

Zbarska S, Holland E, Bloedel JR, Bracha V (2007) Inferior olivary inactivation abolishes conditioned eyeblinks: extinction or cerebellar malfunction? Behav Brain Res 178:128-138. 